\title{
LAS CONTRIBUCIONES MILITARES DEL REINO DE GALICIA DURANTE LA GUERRA DE PORTUGAL
}

\author{
María del Carmen Saavedra Vázquez \\ Universidade de Santiago de Compostela
}

RESUMEN. El desigual conocimiento del grado de participación de los distintos territorios peninsulares en la política militar de la monarquía a partir de 1640 justifica el interés de este trabajo, centrado en el caso de Galicia. El texto se articula en dos partes: la primera, revisa las contribuciones militares realizadas por las Juntas del Reino de Galicia y, la segunda, utiliza las contabilidades de los pagadores militares para verificar su grado de cumplimiento. El análisis de los datos demuestra que la colaboración económica del reino fue especialmente importante en la etapa defensiva de la guerra. Desde el punto de vista social, revela que dicha contribución no permitió a sus élites obtener contrapartidas semejantes a las logradas por las oligarquías de otros territorios, pero les otorgó una experiencia militar que iba a resultar de gran importancia para su promoción en el futuro

Palabras clave: guerra de Portugal, Juntas del Reino de Galicia, impacto de la guerra

ABSTRACT. The unequal knowledge of the degree of participation of the different peninsular territories in the military policy of the monarchy from 1640 justifies the interest of this article, centered on the case of Galicia. It is divided into two parts: the first reviews the military contributions made by the Juntas del Reino de Galicia and the second uses the accounts of the military payers to verify their degree of fulfilment. Analysis of the data shows that eh kingdom's economic collaboration was especially important in the defensive phase of the war. From the social point of view, it reveals that this contribution did not allow these elites to obtain counterparts similar to those achieved by the oligarchies of other territories, but it gave them a military experience that was going to be very important for their promotion in the future.

Keywords: war of Portugal, Assembly of the Kindom of Galicia, impact of the war

Recibido: 9-12-2020 . Aceptado: 16-3-2021.mdelcarmen.saavedra@usc.gal 
EL AÑo 1640 SUPUSO UN IMPORTANTE PUNTO DE INFLEXIÓN en la evolución de la organización militar española, en tanto que la monarquía debió enfrentarse al reto de librar dos guerras en la península. Entre los múltiples efectos de tales desafíos cabe destacar la modificación de los sistemas defensivos y la creación de ejércitos interiores, lo que provocó el cambio de los sistemas de reclutamiento (Rodríguez Hernández, 2012a). Otra de sus consecuencias habría sido el incremento del esfuerzo militar llevado a cabo por provincias y reinos, una política que ya había alentado la Unión de Armas impulsada por Olivares y cuyo fracaso había mostrado las dificultades de ejecución de cualquier intento de repartir las cargas militares (Elliott, 1982). Las urgencias de la guerra, sin embargo, acabarían forzando unas contribuciones en hombres y dinero que afectaron a los territorios de manera desigual, como diferente era su grado de integración en las estructuras políticas de la corona y su mayor o menor implicación en los conflictos bélicos.

Dichas aportaciones iban a canalizarse fundamentalmente a través de asambleas representativas y poderes locales, a quienes la monarquía solicitó servicios particulares que se irían desarrollando en paralelo a la fiscalidad ordinaria, alentando intensos procesos de negociación entre los representantes monárquicos y sus integrantes. Por esta vía tales instituciones habrían obtenido capacidad de intervención en materia de guerra, una realidad que ha sido interpretada tradicionalmente como reflejo de la creciente debilidad de la corona, que hubo de ceder a terceros importantes parcelas de control de la organización militar (Thompson, 1987). Las negociaciones también habrían facilitado la búsqueda de contrapartidas al esfuerzo realizado, como medio de obtener una gratificación de los servicios prestados al rey. Además, el hecho de que las contribuciones militares de los distintos reinos ya no se orientasen únicamente a la defensa propia, ha permitido sostener que supuso un avance hacia la integración territorial, anticipando una tendencia que sería desarrollada en el reinado siguiente (Storrs, 2013).

Estas valoraciones suelen apoyarse en investigaciones realizadas a partir de las actas de las instituciones afectadas, que suelen ser muy prolijas en la descripción de los procesos que condujeron a la concesión de los servicios y en las ventajas solicitadas u obtenidas a cambio. Así se ha hecho en los casos de Aragón, Cataluña, Guipúzcoa, Navarra o Extremadura, trabajos que certifican las múltiples contribuciones realizadas por las poblaciones peninsulares a partir de 1640. Bien entendido que en la mayor parte de las ocasiones la limitación de las fuentes sólo permite analizar las concesiones documentadas y no la totalidad del esfuerzo militar soportado por los territorios bajo la forma de alojamientos, requisas, transportes, etc. Además, las actas apenas proporcionan información sobre el grado de ejecución de los servicios concedidos, más allá de las valoraciones interesadas generadas por las propias instituciones a la hora de negociar nuevos tributos. En consecuencia, nuestro conocimiento del 
grado de participación de los distintos territorios en la política militar de la monarquía sigue siendo limitado.

Esta afirmación resulta especialmente aplicable a lo ocurrido durante la guerra de Portugal, dado que la revuelta catalana ha suscitado la atención preferente de los investigadores hasta la fecha. Y en relación con el conflicto portugués, el hecho de que el principal frente de batalla se situara en Extremadura explica la focalización de la investigación en dicho espacio y la insistencia de los especialistas en los perjuicios sufridos por dicho territorio, especialmente en la fiscalidad bilateral producto de la guerra (Cortés, 1990) y en la reacciones sociales que el esfuerzo bélico iba a provocar (White, 1987).

En el caso de Galicia, carecemos de un trabajo monográfico sobre la guerra de Portugal. El desarrollo de los acontecimientos militares se puede reconstruir parcialmente partiendo de obras de eruditos españoles y portugueses, como Jerónimo Barrionuevo o el conde de Ericeira, o de cronistas locales, como Ávila y la Cueva, historiador de la provincia de Tui. En paralelo, se han comenzado a abordar los efectos del conflicto sobre el territorio partiendo de documentación local (Pérez García, 2006; Santiago Rodríguez, 2013), pero sobre todo recurriendo a las Actas de las Juntas del Reino de Galicia, cuya publicación ha permitido la consulta de un fondo particularmente voluminoso y la elaboración de diversos estudios sobre su contenido. Cierto que la visión que proporcionan es genérica y está condicionada por la naturaleza de la institución, los intereses de las oligarquías municipales de las siete ciudades que la integraban, y las propias fechas de celebración de las reuniones.

En consecuencia, este trabajo pretende completar la información proporcionada por las Actas de las Juntas con los datos obtenidos de las contabilidades de los pagadores militares de Galicia, documentación que se conserva en la sección de Contaduría Mayor de Cuentas del Archivo General de Simancas. Con ello intentamos analizar las contribuciones gallegas desde una nueva perspectiva, procedimiento que ya demostró su utilidad a la hora de abordar etapas anteriores (Saavedra, 2004). Además, dicha fuente no solo permite valorar la importancia que habrían tenido las contribuciones del reino en el conjunto del presupuesto militar, sino también obtener nuevos datos sobre la actividad bélica desarrollada en la región. Partiendo de tales premisas, el trabajo se articula en dos partes, la primera de las cuales revisa las aportaciones comprometidas por las Juntas del Reino, mientras la segunda recurre a las contabilidades de los pagadores militares para verificar su eficacia y obtener una visión más amplia del esfuerzo militar sostenido por el territorio.

\section{La guerra y las contribuciones militares de las Juntas}

La rebelión portuguesa iniciada a finales de 1640 surgió en un escenario internacional convulso, caracterizado por las tensiones militares propias de la guerra de 
los Treinta Años. Dicho conflicto había alcanzado especial virulencia tras el estallido de la contienda franco-española de 1635, que sería responsable de un sustancial incremento de las exigencias bélicas de la Monarquía Hispánica (Domínguez Ortiz, 1960; Artola, 1982; Elliott, 1990; Gelabert, 1990; Borreguero, 2018, p. 253). Aunque el principal episodio de dicho enfrentamiento en la Península Ibérica fue la liberación del cerco francés a Fuenterrabía, en septiembre de 1638, Galicia también iba a experimentar un gran aumento de la actividad militar en dicho periodo.

La formación en el puerto corunés de tres armadas sucesivas con destino a Flandes: las del marqués de Fuentes en 1636, Lope de Hoces en 1637 y Antonio de Oquendo en 1639, y las levas realizadas en el reino para proporcionar reclutas a dichas flotas, iban a convertirse en pruebas fehacientes de la importancia estratégica alcanzada por la región en dicho ciclo bélico. Una realidad que también se pondría en evidencia tras el ataque sufrido por A Coruña en junio de 1639, a cargo de la escuadra francesa del arzobispo de Burdeos (Saavedra, 1996, p.157 y ss.).

En tales condiciones, no sorprende que la Corona hiciera llegar diversas peticiones de hombres a las Juntas del Reino de Galicia en la primera mitad del año 1640, generando un cierto malestar entre los representantes ciudadanos debido a la indefensión padecida por el territorio. En particular, se reconocía la urgencia de mejorar sus fortificaciones, aunque ni el rey disponía de recursos para afrontar dicha tarea, ni las Juntas accedieron a la petición del gobernador de sufragar las obras ${ }^{1}$.

Bien es verdad que el posicionamiento de los representantes de las siete capitales provinciales reunidos en la asamblea era muy heterogéneo y en esencia dependiente de su grado de participación en la actividad militar, una circunstancia compartida con otras asambleas de la época (Truchuelo, 2004, p. 34). Así por ejemplo, la decisión real de alojar en Galicia la infantería de la armada de Antonio de Oquendo, superviviente de la batalla de las Dunas, iba a preocupar sobre todo a A Coruña porque contribuía a agravar los problemas de alojamiento que afectaban a la ciudad y generaba dificultades de abasto $^{2}$. Sin embargo, los diputados solían hacer causa común cuando se trataba de frenar peticiones consideradas excesivas, como ocurrió con motivo de las demandas de reemplazo de 500 hombres que habían sido enviados al ejército de Guipúzcoa en $1639^{3}$.

El estallido de la revuelta catalana en el mes de junio de 1640 añadiría nuevas dificultades a este panorama de creciente esfuerzo militar, de ahí la imposibilidad manifestada por el concejo coruñés de enviar hombres a Molina de Aragón, para acom-

Actas de las Juntas del Reino de Galicia (en adelante, AJRG), vol. 4, pp. 132-134.

Archivo Histórico Municipal de A Coruña (en adelante, AHMC), Libros de Actas (en adelante, LA), sesiones 19 de abril y 29 de julio de 1640 . 
pañar al monarca en la jornada prevista a dicho territorio ${ }^{4}$. Las autoridades locales se encontraban menos dispuestas aún a sufragar empresas de mayor envergadura, como revela su negativa a la petición real de prolongar el tiempo de servicio de la Escuadra de Galicia, cuya gestión se había revelado ruinosa para el reino y cuyas cuentas serían objeto de litigio durante décadas con los hermanos Quincoces y sus herederos ${ }^{5}$.

Con tales antecedentes, la rebelión portuguesa iba a convertirse en una auténtica prueba de fuego para la organización militar de Galicia. De entrada, la guerra con Portugal suponía un cambio en los objetivos estratégicos tradicionalmente asignados al área. La obligación de proteger la frontera terrestre alteraba el sistema defensivo vigente, basado en la protección del litoral desde los presidios de A Coruña y Baiona, aunque recurriendo también a un extenso sistema de milicias, dado que el número de soldados profesionales resultaba insuficiente para garantizar la defensa del territorio. La coordinación de dicha organización era competencia del gobernador y capitán general del reino, que desde finales del siglo XVI disponía de una primera administración militar (pagador, veedor, tenedor de bastimentos...) y un reducido elenco de oficiales, los sargentos mayores, distribuidos a lo largo de los puertos para adiestrar a sus vecinos. También en tiempos de Felipe II se procedió a la fortificación del territorio, aunque iba a tratarse de una tarea incompleta por falta de recursos (Saavedra, 1996, p. 117).

A comienzos de 1641 dicha estructura defensiva se encontraba en condiciones precarias, a juzgar por las quejas manifestadas por las autoridades coruñesas ante la falta de infantería vieja en el presidio, tras su envío a Flandes y Cataluña ${ }^{6}$ También las Juntas del Reino iban a insistir en el asunto, añadiendo nuevas carencias a su relación de necesidades: la falta de corazas padecida por las compañías de caballos, la escasez de armas de fuego, pese al repartimiento efectuado en Galicia para su adquisición en 1639, o la inexistencia de un tren de artillería en la región ${ }^{7}$. Cierto es que a lo largo del conflicto portugués, el frente gallego iba a tener un carácter secundario, pero ello no impidió que Galicia hubiera de realizar un importante esfuerzo militar. Una realidad que se pondría en evidencia sobre todo a partir de 1658, cuando se pasó de una guerra defensiva a otra ofensiva, apuntalada merced a la firma de la Paz de los Pirineos al año siguiente, que ponía fin al conflicto con Francia.

La primera de las tareas que hubieron de acometer las autoridades gallegas fue la de adaptar las fuerzas existentes en la región a las nuevas necesidades militares. Un proceso semejante al desarrollado en la frontera extremeña, aunque mucho menos

AHMC, LA, 22de octubre de 1640.

AJRG, vol. 4, p. 217.

La guarnición coruñesa habría sido una de las más afectadas, de ahí las quejas de su concejo al respecto. AMC, LA, 22 de octubre de 1640.

$7 \quad$ AJRG, vol. 4, p. 240 y p. 272. 
intenso que el protagonizado por los portugueses, obligados no solo a la creación de un ejército, sino también de una completa estructura institucional de guerra (Dores, 2004, pp. 24 y ss.). En Galicia dicho cambio se iniciaría tras el traslado a la frontera del gobernador marqués de Valparaíso, quien se hizo acompañar de los diputados de las Juntas del Reino, reunidos en A Coruña cuando se conoció el levantamiento. Todos se mostrarían presurosos en el cumplimiento de la orden, tras enviar una carta al monarca reiterando su fidelidad a la Corona y manifestando «el xeneral dolor y sentimiento con que en él se a oydo la nueva de la detestable traición del duque de Braganza» ${ }^{8}$.

Desde el punto de vista militar, la principal consecuencia del nuevo estado de cosas sería el práctico desmantelamiento de los presidios, cuyo servicio quedó en manos de milicianos, compañías de labradores que carecían de la adecuada formación militar y padecían múltiples penurias por la falta de socorros ${ }^{9}$. Además, en diciembre de 1640 se procedió al traslado de municiones y pertrechos desde las plazas de A Coruña y Baiona a la frontera, una decisión adoptada en la confianza de que la situación iba a resolverse pronto. Sin embargo, tres meses más tarde la evidencia de que el conflicto se dilataba y la llegada al reino de algunas noticias sobre el apresto de armadas en Francia y Holanda para el socorro de Portugal harían saltar todas las alarmas ${ }^{10}$.

Es verdad que tales amenazas no llegaron a concretarse, aunque tampoco se adoptaron medidas para evitar la desprotección del área. Esto explica la sensación de indefensión que cundía en el litoral y las iniciativas planteadas por algunas ciudades, como Betanzos, que esperaba hacer frente común con A Coruña en su solicitud de refuerzos debido a «la flaqueza della y desta ciudad para resistir las fuerças y armadas del norte» ${ }^{11}$. Sin embargo, la solución arbitrada por las autoridades militares, el envío de nuevos milicianos a los núcleos más expuestos, iba a resultar muy poco eficaz, además de generar graves complicaciones por la falta de alojamientos ${ }^{12}$. De ahí la reiteración de las peticiones de las Juntas para reforzar los presidios del reino, fortificando las plazas de A Coruña y Baiona y dotándolas del número de infantes asignado a su guarnición ${ }^{13}$. Para garantizar la operatividad de las unidades también se consideraba indispensable depurar la nómina de las compañías, eliminando las plazas ocupadas por vecinos en búsqueda de exenciones ${ }^{14}$, y garantizar su supervivencia económica, exigiendo de la monarquía «consignación cierta» para hacer frente a los gastos de mantenimiento ${ }^{15}$.

AJRG, vol. 4, p. 223

AJRG, vol. 4, pp. 298-299.

AJRG, vol. 4, p. 272.

AHMC, LA, 24 de abril de 1641.

AHMC, LA, 10 de mayo de 1641.

AJRG, 18 de mayo de 1644, 9 de julio de 1646 .

AJRG, 5 de enero de 1649 .

AJRG, 5 de octubre de 1644; 9 de abril de 1650; 13 de marzo de 1669. 
La concentración de tropas en la frontera, por su parte, iba a permitir la constitución de dos grandes unidades militares, los ejércitos de Tui y Monterrei. El primero estaría encabezado por el gobernador marqués de Valparaíso, quien debía ocuparse de la protección de la «raya húmeda», esto es, la frontera del Miño, además de la defensa de «todo el terreno que ay desde la ciudad de Santiago, villa de Muros hasta la de la Guarda ${ }^{16}$. Por su parte, al frente del ejército de Monterrei se situaría el marqués de Tarazona, cuya autoridad se extendía no solo al estado de Monterrei, sino también a los obispados de Ourense, Astorga y Lugo. Bajo el mando de ambas autoridades se encontraban esencialmente fuerzas de milicia, cifrándose en 10.722 los soldados naturales del reino que sirvieron en el ejército de Tui hasta el año de $1643^{17}$.

Esta organización defensiva que dividía la frontera en dos grandes sectores reproducía la estrategia aplicada en 1580, cuando se produjo la incorporación de Portugal a la corona de Castilla y se encomendó a los condes de Lemos y Monterrey la dirección de las operaciones militares. También en ese caso los ejércitos habían estado compuestos por naturales, poniendo en evidencia que los sesenta años transcurridos entre ambas contiendas no habían sido suficientes para dotar al reino de una fuerza militar capaz de prescindir de las milicias. Claro está que no se trataba de una particularidad gallega, pues también el ejército de Extremadura iba a caracterizarse por su escasa profesionalidad, hasta que la paz con Francia permitió el traslado a la península de las tropas que luchaban en Flandes y Milán, dotando al frente extremeño de tropas valonas, alemanas e irlandesas (Rodríguez y Rodríguez, 2008, p. 148).

En el caso gallego, la urgencia de la situación explica esa reunión apresurada de tropas milicianas en la frontera, cuya particular configuración otorgaba a la nobleza un papel fundamental en la dirección del contingente, dado que el sistema de milicias descansaba sobre una oficialidad formada por notables locales, en su mayor parte de origen hidalgo y condición señorial. Una importancia redoblada por la reconocida capacidad de recluta atribuida al sector nobiliario, tanto del lado español como del portugués (Dores, 2001, p. 95). Además, la tratadística de la época seguía considerando natural el servicio militar de los nobles y su prestación desde el presupuesto de la voluntariedad. Por ello no sorprende que una de las primeras decisiones adoptadas por las Juntas del Reino consistiera en encargar un estandarte con las armas reales y las del Reino, para enarbolarlo y lograr así que el ejército reunido «sea más copioso, abrigado con los nobles de todo él» ${ }^{18}$.

16 AHMC, LA, 24 de abril de 1641.

17 Según los diputados gallegos, esos milicianos se habían organizado en ocho tercios, sirviendo con 1.710 mosquetes, 4.708 arcabuces, 3.295 picas y chuzos, además de las armas de fuego compradas por los naturales a los 1.009 hombres que carecían de ellas. «Y esto sin la jente y armas con que se formaron los tercios en el exército de Monterrey, que formó el señor marqués de Taraçona de los mismos naturales, que precisamente abían de ser por lo menos otros tanto». AJRG, vol. 5, p. 366. 
Con todo, la necesidad de garantizar la operatividad de las tropas hizo que también se enviaran a Galicia algunos oficiales experimentados, como un nuevo gobernador de la caballería, Baltasar de la Cruz, cuya presencia en el reino en mayo de 1641 motivaría la queja de las propias Juntas, por haber desplazado a quien ya estaba ejerciendo el oficio, don Antonio Salgado Gundín, caballero del hábito de Santiago y señor de la fortaleza de Borrajeiros. Aun tratándose de un oficial con experiencia como capitán de infantería en Flandes y capitán de caballería en Milán, los diputados gallegos motivaban su queja aludiendo no tanto a la capacidad del interesado, como al «desaire» que había sufrido y su buena relación con los soldados, que «por ser natural deste Reyno se animavan en qualquier ocasión» ${ }^{19}$.

Esta insistencia en el componente honorífico de los cargos militares resultaba especialmente ajustada a la situación del cuerpo de caballería, cuyas compañías habían sido reorganizadas en el año 1639, precisamente por don Antonio Salgado, responsable de la formación de un tercio en la provincia de Santiago. Paradójicamente, dicha operación había provocado el malestar de las Juntas en febrero de 1640, al hacerse eco del memorial remitido por varios milicianos, que habían sido apremiados para servir en la caballería y depositar ocho ducados cada uno para la compra de carabinas $^{20}$. Una situación que les llevaba a recordar que «la caballería se debe de rehacer de las personas que tengan caudal y hijosdalgo de los del Reyno que están acostumbrados a andar cavalleros» ${ }^{21}$.

Cierto es que los esfuerzos realizados en la región para levantar compañías a caballo no iban a resultar suficientes para garantizar su defensa. Aunque a finales de 1640 la caballería del reino ya estaba reunida en la frontera, dos años más tarde buena parte de la misma, en torno a 1.400 hombres, acabó siendo trasladada a Cataluña, en una operación dirigida por el marqués de Valparaíso ${ }^{22}$. Los 800 caballeros que habían quedado en Galicia pronto iban a padecer la falta de provisiones y forraje, de modo que serían licenciados en su mayor parte, quedando sólo 300 en Tui y Monterrei ${ }^{23}$. En consecuencia, el gobernador marqués de Tábara debió impulsar la operación de rehacer la caballería en 1644, una tarea llamada a repetirse en adelante, provocando las quejas de algunos de los afectados.

La principal preocupación de las autoridades militares, sin embargo, era el estado de las fuerzas de infantería, de ahí que tras el nombramiento de un nuevo gobernador en abril de 1642, don Martín de Redín, una de sus primeras medidas hubiese consistido en solicitar de las Juntas la concesión de una leva de 16.000 hombres re-

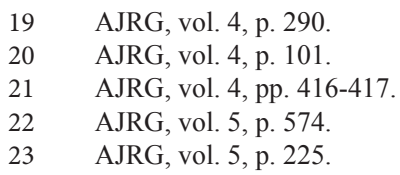


clutados a nivel parroquial (por pilas bautismales), para defensa del reino y en sustitución de las fuerzas que estaban en la frontera. Esta sería la principal contribución de Galicia al esfuerzo de la guerra, una concesión justificada por el gobernador apelando a los excesos y la desigualdad que habían regido la recluta de milicianos hasta entonces. En consecuencia, para lograr la aprobación de los diputados ofrecía efectuar los repartos a la manera tradicional, por tercias y sextas $\operatorname{partes}^{24}, \mathrm{y}$ «con intervención de las Justicias de cada ciudad y no de los capitanes y ministros», además de garantizar el licenciamiento de los labradores que se encontraban en el frente ${ }^{25}$. Pese a dicha prerrogativa, la solicitud iba a generar un intenso debate entre las ciudades gallegas, siendo aprobada por mayoría de votos, los de los diputados de Lugo, Mondoñedo, Ourense y Tui, mientras los regidores de Santiago, Betanzos y A Coruña apelaban de dicha decisión ${ }^{26}$. De hecho, nunca llegarían a reunirse los hombres previstos y a lo largo del conflicto su número iría variando en función de la coyuntura militar y las negociaciones entabladas entre los gobernadores y los representantes del reino (Eiras, 1995, pp. 17-37).

Tabla 1. Evolución del ejército de pilones

\begin{tabular}{|c|c|}
\hline Año & No hombres (teóricos) \\
\hline 1642 & 16.000 \\
\hline 1649 & $4.000(4$ tercios) \\
\hline 1657 & 7.000 (7 tercios) \\
\hline
\end{tabular}

Fuente: AJRG, vol. 5, p. 132; vol. 6, p. 137; vol. 7, p. 189.

Buena parte de los debates generados en torno a los tercios reclutados a partir de las pilas bautismales tenían que ver con los gastos de mantenimiento del contingente. Aunque la concesión se había hecho a condición de que los hombres fueran socorridos por el rey, y entregados por el reino «sin obligación de vestidos ni armas» ${ }^{27}$, las dificultades de la hacienda real pronto hicieron imposible tal compromiso. De ahí las reiteradas peticiones de las Juntas para lograr el pago de sus socorros, insistiendo en la necesidad de ajustar el número de los soldados a la consignación establecida para su sustento o el embargo de las rentas cobradas en el reino para garantizar el socorro de la gente de guerra ${ }^{28}$. En su defecto, parte de las necesidades materiales de los reclutados acabarían siendo sufragadas por el propio reino, de modo que el ejérci-

24 Esto suponía que un tercio de la carga debía ser satisfecho por la provincia de Santiago, el segundo tercio por las de Ourense y Lugo a partes iguales y el tercero por las cuatro provincias restantes: Betanzos, Mondoñedo, Tui y A Coruña, a razón de un onceavo las tres primeras y un quinceavo la última.

25 AJRG, vol. 5, p. 129.

26 AJRG, vol. 5, p. 143.

27 AJRG, vol. 5, p. 313.

28 AJRG, vol. 5, pp. 209, 245 y 259, vol. 6, p. 102. 
to de los pilones acabaría convirtiéndose en una carga no solo humana, sino también económica para Galicia.

Además, su constitución iba a tener algunos efectos colaterales dignos de mención, como las quejas sobre la indefensión del litoral efectuadas por algunas ciudades, como A Coruña ${ }^{29}$. Por otra parte, la creación del ejército de naturales explica que en Galicia no se aplicase el plan de tercios provinciales de 1663 (Contreras, 2003). En contrapartida, las reclutas efectuadas en la región serían aprovechadas para enviar soldados gallegos a otros destinos, básicamente a Flandes, habiéndose calculado en 2.526 hombres los remitidos a este territorio en la primera etapa de la guerra (Rodríguez, 2007, p. 239). Dicho proceso no sólo se haría mediante repartimientos, sino también gracias a soldados voluntarios y reclutas reunidos por asiento, operaciones que habrían movilizado a todos los poderes del reino (nobles, ciudades o eclesiásticos) contando con el apoyo de las autoridades reales ${ }^{30}$.

En paralelo a estas demandas, en Galicia se realizaron algunas levas de marineros, aunque la información disponible tan solo se refiere a casos puntuales, como los 230 marineros embarcados en Pontevedra para la armada real en 1646, o los 16 marineros reclutados en A Coruña por orden del gobernador a comienzos de $1647^{31}$. También se encuentran mal documentados los aportes de hombres para fortificar la frontera, una medida que se habría desarrollado de 1643 en adelante y que tiene claros paralelismos con la adoptada en algunas comarcas portuguesas estudiadas en profundidad, como el Bajo Alentejo (Salvado, 2015, p. 215). Aunque el proceso de construcción de los fuertes gallegos de Goyán o Amorín es bien conocido (Blanco Rotea, 2015), los trabajos realizados en ellos por las poblaciones cercanas sólo están descritos de forma genérica. De hecho, la valoración efectuada por las Juntas en 1669, una vez finalizada la guerra, insistía en que «todas las fortificaciones de la villa de la Guardia asta las Frieiras [...] que son treinta y seis legoas de frontera con Portogal se hiçieron a travaxo de dicho Reino», cifrando en más de diez mil hombres el número de milicianos que se habrían movilizado, por haber llamado «para cada plaça que se fortificaba a dos y a tres mil onbres $\rangle^{32}$.

Al margen del carácter interesado de tales valoraciones, resulta indudable que el conflicto de Portugal exigió una importante contribución humana al reino de Galicia, aunque no sería el único de los aspectos a considerar. Ya hemos visto cómo la constitución del ejército de pilones acabaría teniendo un impacto económico sobre el reino, en tanto que la guerra supuso un considerable incremento de los gastos

AHMC, LA, 24 de septiembre de 1642

AHMC, LA, 20 de noviembre de 1647. El gobernador ordena que las ciudades del reino ayuden al conde de Altamira para la realización de la leva que tenía previsto levantar en el mismo.

AJRG, vol. 5, p. 366 ; AHMC, LA, 21 de enero de 1647.

AJRG, vol. 8, p. 133. 
militares de la Corona y el frente gallego habría sido el peor financiado de la península. Aunque contamos con escasas estimaciones al respecto, los datos disponibles revelan que en 1650 , por ejemplo, los frentes de guerra sufrieron un tratamiento muy desigual, recibiendo el extremeño el $80 \%$ del total de 1.400 .000 escudos de vellón reunidos, mientras se destinaba a Galicia el 20\% restante (Eiras, 1999, p. 23). En tales condiciones, el rey se habría visto obligado a solicitar la colaboración económica de los naturales bajo la forma de servicios o donativos otorgados por las Juntas del Reino. Como es bien sabido, dicho recurso se integraba en una política de alcance general que a lo largo del siglo XVII hizo que la hacienda real recurriese a numerosos expedientes no estrictamente fiscales, especialmente a donativos de ciudades y particulares (Ucendo y Lanza, 2010, p. 31). Una situación que ha sido muy bien documentada en otros territorios, como Aragón durante la guerra de Cataluña (Solano, 1987, p.158; Sanz, 1997, p.125), Navarra a partir de 1630 (Floristán, 2014, p. 186) o Guipúzcoa (2004, p. 162).

Tabla 2. Servicios y donativos concedidos por las Juntas del Reino

\begin{tabular}{|l|l|l|}
\hline Año & \multicolumn{1}{|c|}{ Concepto } & \multicolumn{1}{c|}{ Cantidad (en ducados) } \\
\hline 1642 & Compra de armas de fuego y picas & 25.000 \\
\hline 1643 & Fortificaciones de la frontera & 20.000 \\
\hline 1645 & Camas para soldados & 6.000 \\
\hline 1651 & Servicio de forrajes & 56.938 anuales \\
\hline 1654 & Mantenimiento de la armada & 40.000 \\
\hline 1664 & Ampliación servicio de forrajes & Valor 20.000 carros de paja anuales por 3 años \\
\hline
\end{tabular}

Fuente: AJRG, vol. 5, p.142, p, 187, p. 310, p. 315; vol. 6, p. 279; p. 316; vol. 7, p. 323.

Como es fácil comprobar, los servicios negociados en los años cuarenta tenían como objetivo reforzar el ejército y las defensas fronterizas de manera puntual, mientras en la década siguiente la prolongación del conflicto habría forzado al reparto del esfuerzo militar, implicando al reino de manera permanente en el mantenimiento del ejército de Galicia. En eso consistía el servicio de forrajes otorgado en 1651, el más oneroso de los concedidos por las Juntas debido a la cantidad solicitada, pero sobre todo por su condición de contribución de carácter anual. Esto explica la resistencia de las ciudades a su concesión, que sería objeto de debate desde el momento en que se hizo llegar al reino la petición real, en noviembre de $1648^{33}$. Por eso también la negativa inicial al reparto de los forrajes solicitados y la insistencia de la Corona al respecto, recordando «la obligación de socorrer a los hijos de su patria y miembros 
deste cuerpo del Reyno, cuya cabeza representan los señores deputados del $»^{34}$. Finalmente, los representantes ciudadanos acabarían cediendo, previa elaboración de un escrito con una veintena de condiciones que el rey no llegó a conceder, sobre todo por su pretensión de pagar el servicio por una sola vez. La respuesta monárquica, aun sin aludir directamente a tal circunstancia, resultaba contundente, al argumentar «que las proposiçiones que se hacen son fuera de lo que se ha estilado hasta agora y algunas contra condición de millones» ${ }^{35}$.

El argumento utilizado para justificar la colaboración financiera del reino, la obligación de garantizar el sustento del ejército propio, pronto se vería superado por los apuros de la hacienda real, determinantes del envío a Galicia del consejero de Indias don Joseph Pardo de Figueroa ${ }^{36}$, con el objetivo de lograr la concesión por las Juntas de un donativo de 200.000 ducados a pagar en cuatro años. Una propuesta que se saldaría con la negativa de la asamblea, tras insistir en los muchos gastos originados por la guerra ${ }^{37}$, aunque en su defecto sí se aprobó un servicio de 40.000 ducados a pagar en dos años «para el mantenimiento de la armada» ${ }^{38}$. Además, la asamblea se ofrecía a incrementar esa concesión hasta los 100.000 ducados a cambio del tanteo de alcabalas y cientos, una propuesta que no llegaría a concretarse, pero que resulta reveladora de su interés en obtener contrapartidas del esfuerzo militar.

Ahora bien, no cabe reducir la contribución económica de Galicia a la sola concesión de servicios o donativos en Juntas. La propia asamblea se hacía eco a finales de 1649 de la existencia de «diversos repartimientos e contribuciones en ciudades y provinçias deste Reyno y en sus partidos y lugares para los exércitos del [...], y asta ahora no se les a tomado quenta ${ }^{39}$. Además, también habría que considerar las contribuciones realizadas en especie, aportaciones soportadas por toda la región, aunque con especial incidencia en determinadas localidades y provincias. Este era el caso de A Coruña, cuya condición de presidio y base naval incrementaba periódicamente sus problemas de alojamiento por la llegada de armadas a su puerto, como las 8 compañías de infantes procedentes de Canarias arribadas en 1646 o los soldados de un navío de la armada real en $1650^{40}$.

En 1653 la situación se complicaría aún más, en tanto que la conquista de Irlanda por el ejército de Cromwell iba a provocar el exilio de un buen número de

34 AJRG, vol. 6, p. 128

35 AJRG, vol. 6, p. 603.

36 No fue el único territorio al que acudió, pues también consta su presencia en Guipúzcoa, (veáse Truchuelo, 2004, p. 276, nota 402).

$37 \quad$ AJRG, vol. 6, p. 287.

38 AJRG, vol. 6, p. 316.

39 AJRG, vol. 6, p.119.

40 AHMC, LA, 19 de octubre de $1646 ; 1$ de diciembre de 1650. 
irlandeses, parte de los cuales aportaron al puerto coruñés en busca de refugio. Hasta su envío a Flandes al año siguiente, los irlandeses residentes en Galicia debieron ser distribuidos entre varias localidades, generando importantes gastos de manutención. De ahí las reiteradas peticiones de las Juntas del Reino para que la Corona sufragase la estancia de los «cerca de quatro mil yrlandesses con clérigos, mujeres y niños, que tienen echo de gasto mas de ciento y cinquenta mil ducados» ${ }^{41}$.

Lo mismo cabe decir de la coyuntura iniciada en 1660, cuando se decidió el traslado al frente portugués de algunas tropas estacionadas en Flandes e Italia, lo que suponía enviar desde Ostende a Coruña cerca de 7.000 hombres (Valladares, 1998, p. 183). Tres años más tarde, el concejo coruñés aún seguía protestando por «el trabajo que a tenido en el alojamiento de toda la gente valona y alemana que vino de Flandes $\rangle^{42}$, aunque reconocía que la estancia de la flota había provocado «mucho desorden en el precio de los vinos», pero tras la marcha de la misma «también a cessado el comercio» ${ }^{43}$.

En la Galicia meridional, el presidio de Baiona iba a sufrir igualmente los efectos del conflicto, como revelan algunas investigaciones recientes, que se hacen eco de las quejas de su concejo «porque los vecinos cada día son menos y los que hai sobre quien caen los alojamientos son pobres y no tienen ni pueden con que alojar» (Rodríguez, 2013, p. 238). En este caso, a su condición de núcleo dotado de guarnición había que añadir un importante factor de riesgo: su cercanía a la frontera. De hecho, los núcleos fronterizos iban a sufrir grandes trastornos por alojamientos y contribuciones en especie, padeciendo la presión del ejército propio además de los saqueos y extorsiones del enemigo, como ocurría en Extremadura (Cortes, 1990). Por ello no sorprende que en las Actas de las Juntas del Reino los diputados de las provincias más afectadas, Ourense y Tui, reiteren sus quejas al respecto. Así, en enero de 1649 el representante tudense insistía en la imposibilidad de contribuir a los forrajes de la caballería debido a los muchos trabajos soportados por la población «dexando por aquella parte de coxer los frutos de sus biñas y grangeas, abiéndose arruinado en la çiudad de Tuy barrios enteros echando las casas por el suelo para ponerla en defensa ${ }^{44}$. Además, los perjuicios inherentes a dicha situación han sido verificados en los estudios realizados hasta la fecha sobre localidades concretas, como Verín, Tui o A Guarda, incluyendo testimonios reveladores del impacto de la guerra, como los inventarios que no registran ningún bien mueble porque los portugueses «se los han quemado y llevado todo» (Pérez García, 2006, p. 32).

La suma de todas las aportaciones reseñadas - los servicios concedidos en Juntas, las contribuciones locales o las contribuciones en especie- habrían supuesto

$41 \quad$ AJRG, vol. 6, p. 303.

42 AHMC, LA, 16 de enero de 1663.

43 AHMC, LA, 16 de noviembre de 1646.

44 AJRG, vol. 6, p. 89 
un esfuerzo humano y material importante, aunque muy difícil de valorar en términos cuantitativos. De hecho, solo los servicios canalizados a través de las Juntas permiten una primera aproximación al volumen y cronología de la colaboración gallega en materia militar. También son los únicos que facilitan el acercamiento a las posibles contrapartidas derivadas de la misma, en tanto que las negociaciones entabladas entre Juntas y gobernador permitían a las primeras la presentación de numerosas propuestas y peticiones en materia de defensa y administración del territorio. Esta era una estrategia común a todas las asambleas representativas, incluidas las de territorios no forales, como demuestra el ejemplo asturiano (Tuero, 1978, p. 35). Y en relación con la guerra de Portugal, la contribución realizada por Extremadura ha sido considerada un factor de peso en las negociaciones que condujeron a la concesión del voto en Cortes a esta región en 1651 (Lorenzana de la Puente, 2001, p. 66). Por lo referido a Galicia dicha política daría lugar a multitud de escritos donde se entremezclaban reclamaciones de carácter general con la solicitud de beneficios concretos, bien para las Juntas, bien para las ciudades y sus oligarquías.

Entre las primeras destacan las relativas a la gestión de los contingentes de hombres reunidos en el reino, solicitando el fin de los trasvases de soldados del ejército gallego al de Flandes, y las mismas levas a Flandes ${ }^{45}$. Las Juntas también aspiraban a limitar a dos años el servicio en los tercios de pilones ${ }^{46}$ y a reducir su oficialidad y el número de entretenidos debido a lo elevado de sus sueldos ${ }^{47}$. Otra de las peticiones frecuentes se refería al pago de jornales a los labradores que trabajaban en las fortificaciones del reino y a los encargados de los transportes ${ }^{48}$. La satisfacción de las provisiones de pan, vino, paja o cebada requisadas a los vecinos en distintos momentos de la contienda era otra de las demandas frecuentes en las actas, al igual que la petición de poner fin a los alojamientos en Galicia ${ }^{49}$.

Bien entendido que junto a esas peticiones orientadas a atender al interés general, las ciudades gallegas también aspiraban a obtener algunas ventajas de la concesión de servicios. Las peticiones más frecuentes tenían que ver con su intento de controlar el sistema de reclutas, un interés del que era muy consciente la propia monarquía, de ahí que fuera una de las contrapartidas ofrecidas a cambio de levantar el ejército de 16.000 hombres solicitado al reino. En consecuencia, no sorprende que entre las condiciones del servicio de forrajes elaboradas en 1650 también figurase que «las reclutas o levas de gente han de correr por mano de las ciudades y a su disposición» ${ }^{50}$. Esta pretensión era fruto de las crecientes tensiones generadas entre las ciu-

45 AJRG, vol. 6, p. 82, p.161.

46 AJRG, vol. 6, p. 166

47 AJRG, vol. 6, p. 126, p. 161, p. 605

48 AJRG, vol. 4, p. 287, p. 298; vol. 5 , p. 100, p. 145, p. 573.

49 AJRG, vol. 5, p. 209, p. 252; vol. 6, p. 298.

50 AJRG, vol. 6, p. 161, p. 226. 
dades y los oficiales de milicias, a los que atribuían todo tipo de excesos en la gestión de los contingentes de naturales, de ahí que las Juntas llegaran a solicitar la reducción del número de capitanías por considerarlo excesivo ${ }^{51}$. En el mismo sentido, los representantes ciudadanos también aspiraban a controlar las averiguaciones de los excesos cometidos y del dinero procedente de las multas impuestas a los milicianos ${ }^{52}$, objetivos que acabarían provocando la reacción de su oficialidad en tiempos de la regencia de Mariana de Austria. Una respuesta que adoptaría la forma de «Representación de la nobleza de Galicia» y que pretendía asegurar su intervención en el reparto de los servicios hechos por las ciudades y en los registros de tropas (Murguía, 1911, p.1).

Otro de los grandes objetivos de los diputados gallegos consistía en obtener beneficios para las propias élites que dominaban los gobiernos municipales. De ahí que sus peticiones se orientasen en un doble sentido, por un lado, lograr que los integrantes de los concejos quedaran exentos de llamamientos a campaña ${ }^{53}$, y por el otro, conseguir que los oficios militares recayeran en naturales del reino ${ }^{54}$. Aunque esta última contrapartida ha generado creciente atención de la historiografía en los últimos años (Rodríguez Hernández, 2012b), el caso gallego demuestra que no siempre era el resultado natural de las concesiones de hombres ni su obtención resultaba sencilla.

De hecho, dicho privilegio sería objeto de reiteradas peticiones de los diputados gallegos desde los inicios del conflicto portugués, de modo que aprovecharían la formación del ejército de Tui en 1641 para solicitar que las patentes de alférez mayor y cuatro maestres de campo recayesen en ellos mismos. Dicha petición suponía un cambio sustancial con respecto a la demanda genérica a favor de los naturales realizada en 1639, con ocasión del envío de los primeros soldados gallegos a Flandes, utilizando como argumentos los servicios del reino y las concesiones realizadas a otros territorios (Saavedra, 2017, p. 526). También contrastaba con lo solicitado en febrero de 1640, cuando las Juntas reiteraron la petición de una patente en blanco de maestre de campo y sargento mayor «para inchir en personas naturales deste Reyno de partes, servicios y calidad $»^{55}$.

Aunque los diputados apoyaran su escrito de 1641 en su condición de oficiales de milicias o en los servicios prestados por sus antepasados, resultaba evidente que carecían de la experiencia necesaria para cubrir tales puestos. Sin embargo, ello no impedía que se considerasen capacitados para «acaudillar» las tropas, basándose en consideraciones de carácter honorífico y argumentando que «el Reyno quedará con el

AJRG, vol. 5, p. 209, p. 252; vol. 7, p. 323.

AJRG, vol. 5, p. 120, p. 252.

AJRG, vol. 5, p. 120, p. 165 , p. 190, p. 212

AJRG, vol. 5, p. 100, p. 252, p. 364; vol. 6, p. 128, p. 605.

AJRG, vol. 4, p. 431 
reconosçimiento que debe», y con ellos "yrá la gente con mayor aliento" 56 . Con todo, dicha petición de patentes de alférez mayor y maestres de campo no llegaría a concretarse, lo que no impidió que las Juntas continuaran insistiendo en la conveniencia de que el rey despachase tales puestos en naturales, a imagen de lo que ocurría en otros territorios, sobre todo los que contaban con privilegios forales (Floristán, 2014, p. 193). Cierto es que la asamblea gallega hubo de esperar al reinado de Carlos II para lograr tales concesiones, una circunstancia reveladora de las dificultades propias del proceso negociador (Saavedra, 2017).

En este sentido, cabe resaltar que las Actas de las Juntas también ofrecen abundantes testimonios de las presiones a las que se veían sometidos sus diputados por parte del gobernador para lograr la aceptación de las demandas monárquicas (Eiras, 1999, p. 11). Una situación que se reproducía a nivel local, como revelan las amenazas y represalias sufridas por los regidores coruñeses en diversos momentos de la guerra, por su resistencia a conceder subsidios o proceder al repartimiento de hombres ${ }^{57}$. Tales tensiones eran consecuencia del malestar generado por las continuas demandas de socorros y reclutas entre la población, malestar que no era específico de Galicia, por cuanto están bien documentadas las resistencias o los motines que iban a producirse a uno y otro lado de la frontera (Mackay, 1999; Salvado, 2015). En el caso gallego tan sólo se documenta algún estallido puntual de rabia, como ocurrió en mayo de 1663 en A Coruña, cuando comenzaron a circular por la ciudad algunos pasquines contra las levas, haciendo que las actas municipales se hicieran eco de «gente que anda alborotada» ${ }^{58}$.

La necesidad de salvaguardar la paz pública y garantizar que las contribuciones militares pudieran ser asumidas por el reino explica que las Juntas no solo retrasaran su concesión o redujeran su importe, sino que también negaran en diversas ocasiones las peticiones realizadas por la corona, como revela su negativa a tratar la propuesta real de construir una nueva escuadra de Galicia en 1646, o el donativo solicitado en 1655 para fortificar los puertos del reino ${ }^{59}$. Aun así, sus aportaciones a lo largo del conflicto no parecen haber sido desdeñables, a juzgar por los datos contenidos en las contabilidades militares que son analizadas en el apartado siguiente.

AJRG, vol. 4, p. 245.

Así por ejemplo en el año 1657 se enviaron soldados a las casas de ayuntamiento para impedir la salida de los regidores hasta que aceptasen repartir 400 hombres pedidos por el capitán general. Y poco tiempo después, dado que no acaban de reunirse los soldados repartidos, el oidor auditor general del ejército mandaría sacar bienes a los regidores por valor de 300 ducados, además de amenazar con enviarlos presos al castillo de San Antón. AHMC, LA, 30 de enero y 25 de febrero de 1657.

58 AHMC, LA, 25 de mayo de 1657.

59 En el primer caso se alegaba alegando las muchas cargas que ya soportaba el reino y la necesidad de conocer las cuentas de la Escuadra anterior. AJRG, vol. 5, p. 20; vol. 7, p. 1. 


\section{Las contribuciones del reino según las contabilidades militares}

Como acabamos de comprobar, las Actas de las Juntas demuestran que la guerra de Portugal exigió la realización de un importante esfuerzo militar a Galicia, una realidad que afectó a amplias capas de población, sobre todo en los territorios fronterizos, y que haría imprescindible la colaboración de los poderes del reino. Esto supuso una importante carga para el territorio y otorgó protagonismo en materia militar a las Juntas y las élites locales. Partiendo de tales premisas, el análisis de las contabilidades de los pagadores militares gallegos debería permitirnos obtener nuevos datos que faciliten una valoración más precisa de las características y alcance de dicha colaboración.

Tabla 3. Servicios pagados por el Reino de Galicia (en ducados)

\begin{tabular}{|c|l|c|c|c|}
\hline Cuentas & \multicolumn{1}{|c|}{ Concepto } & Cantidad & Totales & Estimación anual \\
\hline $1650-53$ & Sustento caballería del reino & 54.201 & 54.201 & 13.550 \\
\hline \multirow{2}{*}{$1654-58$} & Sustento caballería y soldados & 76.947 & & \\
& Fortificación de presidios & 31.581 & & \\
& Socorro y flete de irlandeses & 8.449 & & \\
& & & 116.977 & \\
\hline \multirow{2}{*}{$1664-69.395$} & 37.858 & & \\
& Remonta de caballería & 36.046 & & \\
& Forrajes de paja & 35.388 & & \\
& Alojamiento de caballería & & 109.292 & \\
& & & & \\
\hline
\end{tabular}

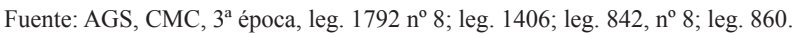

Las cuentas disponibles están organizadas de manera simple, en apartados de ingresos (cargo) y gastos (data) y se caracterizan por una gran rigidez contable, dado que los alcances, las diferencias entre cargo y data, suelen ser mínimos. Es preciso tener en cuenta también otras limitaciones de la fuente: además del problema genérico de referirse a periodos de tiempo diversos — cuatro, cinco o seis años-, la existencia de anualidades sin datos y de partidas incompletas ${ }^{60}$. En consecuencia, las referencias reunidas no pueden considerarse más que el reflejo de una realidad mucho más compleja. A la hora de descender a su análisis, no solo han de tenerse en cuenta las

60 Para el periodo 1650-1653 contamos con la cuenta de Gonzalo de la Concha; para los años 16541658 la cuenta de Esteban Fernández Barbeito, que fue nombrado pagador de la gente de guerra del reino de Galicia el 28 de septiembre de 1653, tras haber ejercido como pagador del partido de Monterrey; para la etapa 1661-1662 la cuenta de Martín Feijoo y para el periodo 1664-1669 la cuenta de Antonio del Río. Archivo General de Simancas (en adelante, AGS), Contaduría Mayor de Cuentas (en adelante, CMC), $3^{\mathrm{a}}$ época, leg. 1792 nº 8; leg. 1406; leg. 842, nº 8; leg. 860. 
limitaciones propias de la fuente, sino también su acotación cronológica, consecuencia de los muchos problemas que plantean las cuentas anteriores a 1650. De ahí que aun habiendo sido utilizadas por Antonio Eiras en alguno de sus trabajos, el propio autor reconozca que «quizá nos confundan más de lo que nos aclaran» (Eiras, 1999, vol. 6, p. 26). A partir de entonces disponemos de mayor información, aunque su calidad varía mucho de unas contabilidades a otras. Aun así, nos proporcionan algunos datos muy valiosos, como la efectividad de los servicios económicos concedidos por las Juntas.

De entrada, las contabilidades ponen en evidencia que no hay una correlación estricta entre los servicios concedidos por las Juntas y los contabilizados por los pagadores. Así, en las Actas figura la concesión y el reparto efectuado en 1654 de 40.000 «para mantenimiento de la armada», que no aparece en las cuentas del pagador. Dicha discrepancia sería fruto de las propias características del donativo concedido en 1654, que estaba destinado a cubrir las necesidades de la Corona (mantener el ejército de Cataluña y reforzar la Armada del Mar Océano) y no las del reino ${ }^{61}$. A cambio, las contabilidades militares incluyen dos contribuciones cuya concesión no aparece en las Actas: por un lado, el servicio pagado por las provincias gallegas para lograr la salida de Galicia de los irlandeses refugiados en 1654, salida que figuraba entre las reclamaciones de las Juntas, y que las contabilidades demuestran que habrían acabado pagando ante la falta de respuesta del rey ${ }^{62}$. Por el otro, el servicio para la fortificación de los puertos del reino, que sí se contabiliza aunque en las Actas solo figure la solicitud monárquica en diciembre de 1655, sin que conste la resolución ${ }^{63}$.

A estas diferencias de partida cabría añadir otra matización importante: aunque los servicios figuren concedidos y cobrados, como ocurre con el servicio más importante, el de forrajes, las contabilidades revelan que este no se cobró íntegramente, pudiendo estimarse lo realmente percibido en una cuarta parte de lo previsto. Aun asumiendo que las cifras concretas puedan no ser exactamente esas, la tendencia que describen parece clara, teniendo en cuenta que tales discrepancias eran habituales en todo tipo de contribuciones y ofrecen una imagen semejante a las concesiones de hombres, en donde existe una gran diferencia entre la concesión teórica y los efecti-

61 AJRG, vol. 6, p. 14, p. 287.

62 Según se indica en dicha partida, el dinero se había recibido «para socorro, condución y flete de irlandeses que se hallaban alojados en Galicia y habían ofrezido las provincias de aquel reino para

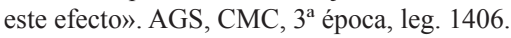

63 La real cédula solicitando un donativo «el más quantiosso que sea posible», figura entre la documentación de las Actas, así como la sesión de las Juntas en la que se presentó a los diputados, que acordaron enviarla a sus ciudades respectivas para su debate «porque no ay poderes de las çiudades para conferir y resolber este negoçio». Y a partir de entonces las Actas no hacen referencia al asunto. AJRG, vol. 7, p. 364, p. 120. 
vos reales ${ }^{64}$. Para tener una visión más ajustada de la realidad cabría referirse a la importancia de esas aportaciones del reino en el conjunto de los ingresos militares. Las contabilidades que manejamos no siempre permiten efectuar un cálculo semejante, pero cuando lo hacen revelan datos interesantes:

Tabla 4. El peso de las contribuciones del Reino en los cargos de pagadores

\begin{tabular}{|c|c|c|c|c|}
\hline Años & Total cargo & Contribuciones & $\%$ cargo & $\%$ total \\
\hline $1654-58$ & 681.499 ducados & $\begin{array}{l}\text { Caballería y soldados } \\
\text { Fortificación } \\
\text { Socorros irlandeses }\end{array}$ & $\begin{array}{l}11,3 \\
4,6 \\
1,2\end{array}$ & 17,1 \\
\hline $1664-69$ & 989.949 ducados & $\begin{array}{l}\text { Remonta de caballería } \\
\text { Forrajes de paja } \\
\text { Alojamiento de caballería }\end{array}$ & $\begin{array}{l}3,8 \\
3,6 \\
3,5\end{array}$ & 10,9 \\
\hline
\end{tabular}

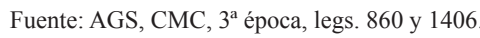

Estos datos muestran que la colaboración económica del reino durante la guerra fue significativa en algunos periodos, pero manteniendo un carácter muy secundario frente al esfuerzo realizado por la Corona. De ahí también que los aportes gallegos fuesen más importantes en los años cincuenta que al final del conflicto, cuando la monarquía hizo un gran esfuerzo para solventar la rebelión portuguesa. Por otra parte, dichas contribuciones tampoco habrían sido las mayores del siglo XVII, dado que en 1624-1625 el servicio para la construcción de la Escuadra de Galicia llegó a suponer el 25\% de los ingresos del pagador gallego (Saavedra, 2004b, p. 349). Aunque tales datos rebajen la magnitud del esfuerzo económico realizado por Galicia, las propias contabilidades revelan que no cabe restringirlo al cobro de los servicios concedidos por las Juntas. Si descendemos al detalle de las cuatro contabilidades disponibles, se trata de una cuestión fácil de comprobar.

La primera cuenta con la que contamos, la de 1650-1653 fue elaborada por el pagador Gonzalo de la Concha, quien se hizo cargo del oficio en 1642, tras haber servido durante años a su padre, el también pagador Blas de la Concha. Se trata de una contabilidad de escasa calidad porque tanto el cargo como la data están incompletos, aunque su lectura no resulta totalmente inútil. De entrada, permite comprobar la existencia de esa fiscalidad bilateral que figura tan difuminada en las actas de la asamblea gallega. Así, entre las partidas de ingresos aparecen 1.022 ducados en concepto de «dinero procedido de repartimientos que se hicieron en el reino de Galicia y otros géneros que se entregaron para gastos y socorro de la gente de guerra que sirve en él». Se trata de una partida heterogénea, que incluye repartimientos de carácter general

64 El 27 de mayo de 1654 el diputado de A Coruña en las Juntas reconocía que «últimamente el ano pasado se an repartido sesenta y dos mil ducados de forrajes, que no se an podido acabar de cobrar en algunas provincias por no tener los pobres naturales con qué pagarlo». AJRG, vol. 6, p. 303. 
(medias annatas de oficios de Tui, segunda jornada de Aragón en la provincia de Tui...), pero también algunos repartimientos locales, pagados por las villas de Bouzas y Vigo, o el valle de Fragoso, para evitar los alojamientos de tropas, unos apuntes que podrían considerarse la punta del iceberg de muchas otras contribuciones similares. Y no sería el único indicador de la presión militar soportada por Galicia, pues en la misma cuenta consta que el pagador había recibido 8.263 ducados en concepto de condenaciones, fundamentalmente «multas a soldados de milicia por no haber acudido a los llamamientos de la frontera ${ }^{65}$. Esto no sitúa ante un tercer nivel de presión militar, el ejercido directamente sobre los individuos, que no sólo se tradujo en reclutas y levas, sino también en pagos en dinero.

La contabilidad no solo certifica que la aportación gallega al esfuerzo de la guerra habría sido superior a la que reflejan las actas, sino también el esfuerzo militar en sí mismo. Así, revela que la actividad naval ha sido muy infravalorada en la documentación manejada hasta la fecha, y de manera especial en las Actas de las Juntas. En el apartado de gastos contabilizados en 1650-1653 se conservan 13 partidas, correspondiendo la mayor a los gastos y compra de bastimentos para la armada, por un importe de 104.780 ducados. Aunque el apunte contable no especifica cómo se distribuyó dicha cantidad, otras partidas permiten suponer que en su mayor parte tendría que ver con el «flete y conducción de 1.492 plazas de infantería irlandesa desde el puerto del presidio de la Coruña al de San Sebastián». Y no habrían sido las únicas operaciones de transporte marítimo efectuadas entonces. En la misma cuenta se da noticia del traslado también a San Sebastián de dos compañías de leva con 160 soldados «que se formaron de las del exército de Galicia» y del transporte de los franceses que se hallaban prisioneros en el reino y fueron enviados en 1651 y 1652 «a servir al remo en las galeras de España».

También las levas efectuadas en Galicia para enviar soldados a Flandes habrían contribuido a engrosar las operaciones navales en la región, aunque en este caso sería por cuenta de los fletes pagados a particulares para su traslado desde A Coruña a Ostende. Cierto que los pagos no aparecen individualizados, de modo que los 7.168 ducados gastados en dicha partida incluían también el pago «a diferentes soldados que levantó en el reino de Galicia don Pedro de Vilela, conde de Lences, de orden de S.Magd.». Y no es la única noticia disponible sobre los gastos provocados por tales levas, pues en la misma cuenta figuran 8.236 ducados pagados a los soldados de la leva de don Juan Pardo de Figueroa. De este modo, la contabilidad de 1650-1653, pese a estar incompleta, da cuenta de la complejidad del escenario militar gallego, en el que los esfuerzos económicos no solo hubieron de dirigirse al mantenimiento de tropas en la región, sino también al desarrollo de las funciones militares tradicional- 
mente ejercidas por Galicia: servir como base de la armada real y espacio de recluta de soldados.

Dicha situación se puede enjuiciar mejor recurriendo a la segunda contabilidad disponible, la de 1654-1658, elaborada por Esteban Fernández de Barbeito, pagador de la gente de guerra del reino en Galicia desde septiembre de 1653, tras haber servido varios años como pagador del partido de Monterrei ${ }^{66}$. Se trata de una contabilidad incompleta en alguno de sus apartados y organizada en torno a dos grandes bloques: presidios y ejército, en cada uno de los cuales figuran servicios pagados por el reino, tal y como puede comprobarse en la tabla $\mathrm{n}^{\mathrm{o}} 5$.

Tabla 5. Cargo del pagador, 1654-1658 (en maravedís)

\begin{tabular}{|l|r|r|r|}
\hline \multicolumn{1}{|c|}{ Concepto } & Cantidad total & En plata & \% del total \\
\hline Presidios & 34.645 .486 & & 13,5 \\
\hline Alcance cuenta anterior & 1.959 .131 & 62.280 & 1,23 \\
\hline Donativo para irlandeses & 3.168 .616 & 1.460 .016 & \\
\hline Recibido para levas marineros & 2.260 .082 & & 4,6 \\
\hline Donativo para fortificación & 11.843 .000 & & \\
\hline Recibido por presas & 15.414 .657 & & 86,5 \\
\hline Ejército & 220.916 .789 & & 11,3 \\
\hline Recibido del asentista del ejército & 97.106 .230 & & \\
\hline Servicio de las provincias & 28.855 .205 & & \\
\hline Multas de soldados de milicia & 2.445 .461 & & \\
\hline Dinero para compras hospital Tui & 557.911 & & \\
\hline Dinero para compras bizcocho & 208.187 & & \\
\hline Dinero procedente presas ganado & 330.344 & & \\
\hline Dinero procedente presas navío & 9.281 .154 & & \\
\hline Indeterminados & 82.132 .297 & & \\
\hline Total & 255.562 .275 & & \\
\hline
\end{tabular}

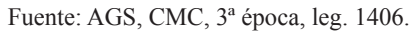

Los datos certifican que la mayor parte de los ingresos del pagador gallego se orientan a hacer frente al coste del ejército estacionado en Galicia (86,5\%), aunque en la cuenta de gastos esa proporción baja un poco $(84,4 \%)$. Tal diferencia podría deberse al pago con cargo a la cuenta del ejército de los sueldos y socorros de la infantería de los presidios, lo que supuso 4.693.058 maravedís de gastos, que fueron pagados sin contar con una partida de ingresos específica. Esto explica que en el apartado de 
cargo de presidios figuren conceptos, como lo «recibido para levas de marineros», lo «recibido por presas» o el donativo para irlandeses, que se vinculan a la actividad naval desarrollada desde el puerto coruñés, pero no al socorro de su guarnición.

En todo caso, la prioridad del mantenimiento de tropas era reconocida por la hacienda real, y de ahí que el 44\% del dinero destinado al ejército gallego fuera proporcionado por don Martín Rodríguez de la Vega, administrador de los millones de Galicia desde 1649, quien corría con el asiento hecho por su hermano don Ambrosio, «para la asistencia del exército del». Mediante dicho mecanismo se buscaba el doble objetivo de garantizar la supervivencia de las tropas y vincular su pago a la recaudación de las sisas en el reino. Bien entendido que dicha aportación resultaba claramente insuficiente, como también reconocían las propias Juntas al destinar su mayor contribución (28.855.205 mrs.) al pago de socorros a los soldados pilones y los forrajes de la caballería del ejército gallego.

Aunque el cargo figure incompleto debido a la existencia de seis partidas sin identificar, el conjunto de los datos inciden en una cuestión de gran interés, como es la importancia que habría podido tener la colaboración gallega en la estrategia militar de la corona. De hecho, el reino habría destinado el grueso de sus aportaciones al mantenimiento de las tropas gallegas, pero el peso de su contribución en el conjunto de los ingresos de ejército (13\%) es muy inferior al que supone en el cargo de los presidios $(43,1 \%)$. Esto vendría a demostrar que la relevancia de sus aportaciones no ha de juzgarse únicamente en función de las cantidades pagadas, sino también de su destino, en tanto que en este periodo la colaboración gallega habría resultado crucial para cubrir aquellos aspectos de la actividad militar - la fortificación de los presidios y el traslado de irlandeses - que la Corona no podía acometer. Esta circunstancia constituye un testimonio revelador de la confluencia de intereses existente entre el rey y las Juntas, pero también de las diversas motivaciones subyacentes a la colaboración de estas últimas: la obligación moral de sostener a los soldados de la tierra en un caso, las ventajas inherentes a la salida de los irlandeses del reino en el otro, y la necesidad de garantizar la defensa del territorio promoviendo la fortificación de los presidios en tercer lugar.

Una rápida lectura de las partidas de gastos proporciona algunos otros elementos dignos de comentario, entre ellos el que las contribuciones del reino se hicieran mayoritariamente en vellón, salvo la partida destinada al socorro y transporte de los irlandeses que habían de pasar a «Flandes, Badajoz y otras partes». Esta circunstancia tiene que ver con la resistencia habitualmente mostrada por las tropas mercenarias a aceptar pagos de salarios en vellón, situación que contrasta con los salarios pagados a las tropas estacionadas en Galicia, que sí se hicieron en la moneda corriente en el país. $\mathrm{Y}$ en relación con la satisfacción de dichos salarios, cabe subrayar también la distinción que figura en la contabilidad entre lo pagado a la infantería, caballería y artillería 
(75.271.067 mrs.) y lo pagado al «capitán general, ministros, oficiales que gozan del sueldo cada mes en el dicho exército cerca de la persona de dicho capitán general» (69.061.541 mrs.). Lo elevado de esta última cantidad explica las peticiones efectuadas por las Juntas para que se redujera la nómina de los oficiales que rodeaban al gobernador, un objetivo que se revela realista, pero que aun así no llegarían a alcanzar.

Si descendemos al detalle de la principal contribución del reino, la destinada al pago del ejército de Galicia, podemos encontrar algunos otros elementos dignos de mención. De entrada, permite comprobar las grandes diferencias contributivas que se registran entre unos años y otros, así como la distinta naturaleza de los contribuyentes. Una realidad que se agranda tras la lectura de los datos disponibles para el año 1658. Aunque los registros están incompletos, en ellos consta que entre enero y junio de ese año diversos particulares habrían ingresado un total de 18.698 reales para quedar exentos de servir en la caballería. Dicha realidad vuelve a incidir en el hecho ya señalado de que la presión militar y las contribuciones del reino no sólo se canalizaban a través de repartimientos provinciales o locales, sino también mediante aportaciones directas satisfechas individualmente, que resultan muy difíciles de rastrear. Con todo, es verdad que el grueso de las contribuciones se realizaba a nivel provincial, de ahí el interés inherente al análisis de dicho reparto, como revela la tabla $n^{\circ} 6$.

Tabla 6. Dinero de las provincias para el ejército de Galicia (reales de vellón)

\begin{tabular}{|l|c|c|c|c|c|}
\hline & 1654 & 1655 & 1656 & 1657 & Total \\
\hline Santiago & $\begin{array}{l}\text { Infantería: } 49.041 \\
\text { Caballería: } 23.678\end{array}$ & I: 131.524 & I: 77.685 & I: 20.968 & I:279.218 \\
& & & & & C:23.678 \\
\hline Lugo & & Inf: 112.324 & Inf: 92.561 & Inf: 6.039 & I:210.924 \\
\hline Mondoñedo & & Inf. 85.525 & Inf. 44.169 & Inf. 14.723 & I:144.417 \\
& & & & Cab. 33.334 & C: 33.334 \\
\hline Betanzos & & Cab. 16.134 & & & C: 16.134 \\
\hline Viveiro & & Cab. 4.560 & & Inf. 4.970 & I: 13.718 \\
& & Inf. 329.373 & Inf. 223.163 & Inf. 46.700 & I: 648.277 \\
\hline TOTAL & Infantería: 49.041 & Cab. 20.694 & & Cab. 40.000 & C:84.372 \\
\hline
\end{tabular}

Fuente: AGS, CMC, 3ª época, leg. 1406.

El primer elemento a destacar sería que el pagador solo registra las contribuciones de algunas provincias, lo que vendría a demostrar que las más afectadas por la guerra, Tui, Ourense y Coruña, que solicitaron reiteradamente quedar exentas de tales repartimientos, lo habrían sido por la vía de los hechos en este periodo. La tabla 
también certifica que Santiago y Lugo fueron las principales contribuyentes, sobre todo la primera, que habría satisfecho el $41,3 \%$ del total, frente al 28,7\% de Lugo y el $24,26 \%$ de Mondoñedo. Las contribuciones de las dos primeras, y en particular la de Santiago, no suponen mayor sorpresa, por tratarse de las provincias con mayor carga fiscal en los repartimientos tradicionales de las Juntas, por tercias y sextas partes, pero el caso de Mondoñedo resulta llamativo por su condición de provincia pequeña y habitualmente poco gravada. Parte de la explicación podría residir en su lejanía al escenario de la guerra, que le permitía cumplir mejor el compromiso de mantener a sus soldados, pero otra parte tendría que ver con la importante contribución hecha a la caballería en 1657, un pago efectuado para evitar su alojamiento en la capital provincial. Y una decisión que no sorprende teniendo en cuenta el temor que provocaban los alojamientos de tropas en las zonas más afectadas por la guerra (Caro, 2012, p. 214). De ahí que en la tabla también figuren pagos similares en los casos de Betanzos en 1655 y Viveiro en 1657, unas contribuciones de naturaleza muy distinta a las efectuadas por las provincias, destinadas a mantener a su propia infantería.

Al margen de las cifras concretas, los datos demuestran que la contribución del reino era difícil de cobrar y muy irregular en su aplicación en el tiempo y en el espacio. Aunque considerada en su conjunto, dicha colaboración resultaba vital para la Corona en ese tiempo de guerra defensiva, cuando se trataba de mantener la organización militar bajo mínimos. Cabe plantearse qué habría ocurrido a partir de 1659, cuando la guerra de Portugal entra en la nueva fase de guerra ofensiva y el fin del conflicto catalán permita dirigir parte del esfuerzo militar al escenario portugués.

En el caso gallego, para analizar esa etapa disponemos de dos contabilidades: la primera es la rendida por Martín Feijoo, que sirvió el oficio de pagador de manera interina, debido al fallecimiento del pagador Esteban Fernández de Barbeito, y por orden del gobernador del reino, el marqués de Viana. Debido a tal circunstancia solo elaboró la cuenta correspondiente a 4 meses y medio, entre 1 de octubre de 1661 y 15 febrero de 1662. La segunda contabilidad fue realizada por Antonio del Río como pagador titular, tratándose de una cuenta completa entre octubre de 1664 y 19 diciembre de 1669, de ahí que centremos el análisis en esta última. Con todo, conviene señalar un aspecto interesante de la cuenta de Feijoo: el 73\% de los ingresos que figuran en su cargo corresponden a dinero recibido del tesorero de la Casa de la Moneda de A Coruña «por quenta de dos libramientos de 80.000 escudos para la gente que se esperaba de Flandes, los 50.000 para sus socorros y los 30.000 para bastimentos». Dicho apunte certifica el cambio de escenario que se produjo a comienzos de los años sesenta, cuando la firma de la paz con Francia permitió la llegada a la península de soldados procedentes de los Países Bajos, mostrando la operatividad de la vertiente gallega del camino de Flandes. Lamentablemente, la cuenta de Feijoo y la de Antonio del Río no son correlativas, lo que impide valorar la importancia de tales movimientos de tropas 
en las contabilidades de los pagadores gallegas. En contrapartida, la cuenta de Antonio del Río ofrece la posibilidad de ir más allá de la guerra de Portugal, por cuanto se refiere también a la situación del año 1669.

Tabla 7. Cargo de Antonio del Río, 1664-1669 (en maravedís)

\begin{tabular}{|l|r|r|r|}
\hline \multicolumn{1}{|c|}{ Concepto } & En vellón & En plata & \% del total \\
\hline Alcance cuenta anterior & 12.353 .718 & & 3,32 \\
\hline Dinero para ejército & 204.652 .127 & & 55,12 \\
\hline Dinero para infantería y transporte a Flandes & 29.571 .502 & 26.580 .748 & 15,12 \\
\hline Remonta caballería & 14.197 .040 & & 3,8 \\
\hline Alojamiento caballería & 13.270 .778 & & 3,5 \\
\hline Forrajes de paja & 13.517 .498 & & 3,6 \\
\hline Dinero para hospitales & 16.830 & & 0,004 \\
\hline Dinero de embargo & 1.531 .904 & 1.341 .876 & 0,77 \\
\hline Dinero derecho del tabaco & & 1.360 .000 & 0,36 \\
\hline Dinero para envío caballos a Cataluña & 1.360 .000 & & 0,36 \\
\hline Compra bastimentos para armada & 972.332 & & 0,26 \\
\hline Dinero de represalia de franceses & 272.000 & & 0,07 \\
\hline Dinero de presas de navíos & 2.092 .190 & 13.257 .518 & 4,13 \\
\hline Multas de plantíos & 1.059 .134 & & 0,28 \\
\hline Dinero para transporte bizcocho ejército & 202.538 & & 0,05 \\
\hline Dinero de extraordinarios & 32.693 .850 & & 89,5 \\
\hline ToTAL & 327.763 .421 & \multirow{2}{*}{4.467 .742} & \\
\hline
\end{tabular}

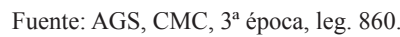

Considerado en su conjunto, el grueso del presupuesto aparece centrado en dos conceptos principales: el mantenimiento del ejército estacionado en Galicia y el traslado de tropas a Flandes, lo que resulta acorde con el momento de transición en el que se encuadra dicha contabilidad. Así, el fin de la guerra de Portugal y la decisión de trasladar a Flandes a buena parte de los efectivos del ejército gallego, explica que descienda la importancia del primero de los capítulos, aunque siga destinándose al mismo algo más de la mitad de los ingresos. Su origen también registra alguna novedad: además del dinero aportado por los asentistas del ejército don Manuel y don Bartolomé Montesinos, y de las cantidades procedentes de algunas rentas reales en el reino, en la cuenta figuran también 3.000 doblones de a dos escudos de oro enviados desde Madrid por orden real y «a cuenta de 30.000 escudos que se sirvió mandar proveer a distribución de don Luis Poderico, gobernador y capitán general [...] para que pudiese acudir prontamente a lo que se ofreciese en la frontera». Este y otros 
cargos semejantes son testimonio de un último intento monárquico para lograr el sometimiento de Portugal, un esfuerzo final que iba a resultar tan tardío como inútil.

De ahí que el segundo gran capítulo del cargo se destine al socorro de la infantería levantada en el reino de Galicia, la compra de bastimentos para los bajeles de la Armada del Mar Océano que se encontraban en la ría de Vigo en el año 1667 y la paga de los fletes de los barcos contratados para completar el pasaje de las tropas a Flandes. Dicha operación era consecuencia del estallido de la guerra de Devolución y tenía como objetivo el refuerzo del ejército español en los Países Bajos con infantería y caballería desmontada procedente de Galicia, mientras los caballos eran enviados a Cataluña. Se trataba de una empresa costosa y que requería disponer de moneda de plata, difícil de conseguir en la región, por lo que algunas partidas menores del cargo, como el dinero procedente del derecho del tabaco en Canarias, cobrado en plata, presentaban un interés suplementario y explican su aparición por primera vez en las cuentas gallegas.

En otro orden de cosas, la contabilidad de Antonio del Río permite comprobar no sólo la pérdida de importancia de las contribuciones gallegas en el conjunto de los ingresos del pagador, sino también los cambios experimentados por las mismas en los últimos años de la guerra de Portugal. De hecho, el grueso del esfuerzo se destina ahora a la caballería y además mediante tres conceptos de naturaleza distinta. Por un lado, el tradicional servicio de forrajes, con el que contribuían las provincias gallegas al sustento de la caballería del reino. Por el otro, una aportación que ya aparecía en las cuentas anteriores y que ahora parece haberse extendido: las contribuciones realizadas por provincias y ciudades para evitar el alojamiento de la caballería en sus plazas, una contribución en la que figuran pagos realizados por la ciudad y provincia de A Coruña, Mondoñedo, Betanzos, la villa de Viveiro y la ciudad y provincia de Santiago. Y por último, una contribución de carácter personal: los 14.197.040 maravedíes pagados por los escribanos y «otras personas del dicho reino», que se destinaron a sufragar la remonta de la caballería del ejército. De este modo, la etapa final de la guerra se perfila como un periodo de financiación compleja, en el que la Corona debió redoblar sus esfuerzos para desarrollar una estrategia militar más ofensiva, mientras el reino reducía sus aportaciones y trataba de eludir obligaciones militares. Bien entendido también que el final del conflicto no pondría fin a las obligaciones militares de la región ni a las contribuciones de Galicia al esfuerzo de la guerra, como hemos tenido ocasión de analizar en otros trabajos (Saavedra, 2011, 2017). 


\section{Conclusiones}

La guerra de Portugal supuso un importante esfuerzo humano y económico para el reino de Galicia, parte del cual fue canalizado a través de las contribuciones concedidas por su asamblea representativa, las Juntas del Reino. El análisis de dichas contribuciones a través de la documentación generada por la propia institución muestra una realidad incompleta, porque en ellas no se da cuenta de todo el esfuerzo militar realizado, en particular por lo referido a las contribuciones en especie o las negociadas con otros poderes. Por eso el cotejo de las informaciones procedentes de las actas de las Juntas con las cuentas de los pagadores militares gallegos ofrece una perspectiva de análisis interesante. Así, permite comprobar que las contribuciones directas del reino fueron secundarias frente al esfuerzo militar de la realeza, pero de gran importancia en algunos periodos para hacer frente a gastos extraordinarios. También revela que esa colaboración sería más importante en la etapa defensiva de la guerra, cuando la monarquía dirigía sus esfuerzos al frente catalán, que en los años sesenta, cuando la paz de los Pirineos le permitió centrar la atención en el conflicto portugués.

Además, la comparación entre las contribuciones concedidas en Juntas y las realmente contabilizadas demuestra que los pagos reales fueron muy inferiores a lo concedido y muy irregulares en el tiempo y en el espacio. Esta constatación podría contribuir a explicar la paradoja existente entre las fuentes impresionistas, empeñadas en mostrar un territorio agobiado por la guerra y los análisis estadísticos efectuados a escala regional, que certifican el crecimiento agrario y demográfico registrado en Galicia durante dicho periodo. Es verdad que ni las contribuciones concedidas en Juntas ni las contabilizadas por los pagadores militares revelan la verdadera importancia y el coste de las aportaciones efectuadas en especie bajo diversas formas: alojamientos de tropas, requisas de alimentos, trabajo en las fortificaciones, etc. De ahí que la imagen a gran escala proporcionada por las fuentes institucionales no resulte incompatible con un considerable impacto de la guerra a nivel local, tal y como revelan las fuentes impresionistas y los testimonios personales.

En otro orden de cosas, el análisis de los datos demuestra que esa contribución gallega no habría permitido a las élites del reino obtener contrapartidas semejantes a las logradas por las oligarquías de otros territorios. La propia naturaleza del conflicto explicaría tal desenlace, en tanto que la colaboración militar pretendía asegurar la propia defensa, haciendo que el rey no considerase tan necesario incentivar sus aportaciones mediante la concesión de privilegios. Bien entendido también que la experiencia militar obtenida por la hidalguía gallega en la guerra de Portugal iba a convertirse en un importante mecanismo de promoción social 
en adelante. Una evidencia que refuerza la visión de la guerra de Portugal como un conflicto que contribuyó a transformar la organización defensiva de Galicia y a facilitar la integración de los gallegos en las estructuras militares sostenidas por la Corona.

\section{AGRADECIMIENTOS}

La edición de este trabajo ha sido posible gracias a la ayuda del Programa de Grupos de Potencial Crecemento concedida por la Consellería de Cultura, Educación e Universidade da Xunta de Galicia al GI-1921 de la USC (Referencia: GPC, ED 431B 2021/06). 


\section{Bibliografía}

Andrés Ucendo, José Ignacio y LanZa García, Ramón (2010), «Presentación. Hacienda y economía en la Castilla del siglo XVII», Studia Historica. Historia Moderna, 32, pp. 23-46.

Artola, Miguel (1982), La Hacienda del Antiguo Régimen, Madrid, Alianza Editorial.

Blanco Rotea, Rebeca (2015), Arquitectura y paisaje. Fortificaciones de frontera en el sur de Galicia y norte de Portugal, Vitoria, Facultad de Letras, [Tesis Doctoral inédita].

Borreguero Beltrán, Cristina (2018), La Guerra de los Treinta Años 1618-1648: Europa ante el abismo, Madrid, La Esfera de los Libros.

CARo del Corral, Juan Antonio (2012), «La frontera cacereña ante la Guerra de Restauración de Portugal: Organización defensiva y sucesos de armas», Revista de Estudios Extremeños, tomo 68, pp. 187-226.

Contreras Gay, José (2003), «La reorganización militar en la época de la decadencia española (1640-1700)», Millars. Espai i Història, XXVI, 2003, pp. 131-154.

Cortés Cortés, Fernando (1990), Guerra e Pressão Militar nas Terras de Fronteira 1640-1668, Lisboa, Livros Horizonte.

Domínguez Ortiz, Antonio (1960), Política y Hacienda de Felipe IV, Madrid, Editorial de Derecho Financiero.

Dores Costa, Fernando (2001), «Formação da força militar durante a guerra da Restauração», Penélope: revista de història e ciências sociais, 24, pp. 87-119.

Dores Costa, Fernando (2004), A Guerra da Restauração, 1641-1668, Lisboa, Livros Horizonte.

Eiras Roel, Antonio (1995), «Introducción al volumen 5: las Juntas del Reino de Galicia de 1642 a 1647», Actas de las Juntas del Reino de Galicia, Santiago de Compostela, Dirección Xeral do Patrimonio Histórico e Documental, volumen 5, pp. 11-58.

Eiras Roel, Antonio (1999), «Introducción al volumen 4: las Juntas del Reino de Galicia y la política fiscal de 1648 a 1654», Actas de las Juntas del Reino de Galicia, Santiago de Compostela, Dirección Xeral do Patrimonio Histórico e Documental, volumen 6, pp. 4-41.

Elliott, John H. (1982), «El programa de Olivares y los movimientos de 1640», en Jover Zamora, Jose María (dir.), Historia de España fundada por Ramón Menéndez Pidal, Madrid, Espasa Calpe, tomo 35, pp. 335-523. 
Elliott, John H. (1990), El Conde-duque de Olivares, el político en una época de decadencia, Barcelona, Crítica.

Floristán ImízCOz, Alfredo (2014), El reino de Navarra y la conformación política de España (1512-1841), Madrid, Akal.

Gelabert González, Juan E. (1990), «El impacto de la guerra y del fiscalismo en Castilla», en García Sanz, Ángel y Elliott, John H. (coords.), La España del Conde Duque de Olivares, Valladolid, Universidad, pp. 555-574.

GonzÁlez Abellás, Isaac (2006), «Una demografía de frontera en el siglo XVII: el valle de Monterrei 1580-1699», en Pérez García, José Manuel y López Díaz, María (eds.), Cuadernos Feijonianos de Historia Moderna III, Santiago de Compostela, Tórculo Editores, pp. 9-29.

Lorenzana de la Puente, Felipe (2001), «Extremadura. 1640-1668. Tiempo de guerra, tiempo de política», I Congreso Internacional do Caia e Guadiana, Elvas, Câmara Municipal de Elvas, pp. 55-70.

MACKay, Ruth (1999), Los límites de la autoridad real: resistencia y obediencia en la Castilla del siglo XVII, Salamanca, Junta de Castilla y León, 2007.

Murguía, Manuel (1911), «Representación de la Nobleza de Galicia al Rey Carlos II y a su madre la Reina Regente», Boletín de la Real Academia Gallega, año 6, no 49, pp. 1-5, y no 51 y 52, pp. 53-57.

PÉrez GarcíA, José Manuel (2006), «Consecuencias económicas y demográficas de la guerra de independencia de Portugal en el bajo Miño: demografía de frontera en una etapa belicista (1630-1679)», en Pérez García, José Manuel y López Díaz, María (eds.), Cuadernos Feijonianos de Historia Moderna III, Santiago de Compostela, Tórculo Editores, pp. 53-102.

Rodríguez Hernández, Antonio José, (2007), «De Galicia a Flandes: reclutamientos y servicio de soldados gallegos en el ejército de Flandes (1648-1700)», Obradoiro de Historia Moderna, 16, pp. 213-251. <https://doi.org/10.15304/ ohm.16.602>.

Rodríguez Hernández, Antonio José (2012a) «Los primeros ejércitos peninsulares y su influencia en la formación del Estado Moderno durante el siglo XVI», en González Enciso, Agustín (coord.), Un Estado militar: España, 1650-1820, Madrid, Editorial Actas, pp. 19-64.

Rodríguez Hernández, Antonio José (2012b), «Servir al rey con hombres. Recompensas concedidas a élites y representantes del rey por su colaboración en el reclutamiento (1630-1700)», en Esteban Estríngana, Alicia (ed.), Servir al rey en la Monarquía de los Austrias. Medios, fines y logros del servicio al soberano en los siglos XVI y XVII, Madrid, Sílex, pp. 415-443. 
Rodríguez Hernández, Antonio José y Rodríguez Rebollo, Patricia (2008), «Entre la guerra y la paz: la guerra de Restauración portuguesa en Extremadura y las negociaciones de paz con Portugal (1640-1668)», en Lorenzana de la Puente, Felipe y Mateos Ascacibar, Francisco J. (coords.), VIII Jornadas de Historia en Llerena. Iberismo. Las relaciones entre España y Portugal. Historia y tiempo actual, Llerena, Sociedad Extremeña de Historia, pp.141-154.

Rodríguez Rodríguez, Santiago (2013), «La guerra de Restauración de Portugal en Baiona y sus consecuencias», en López Díaz, María (ed.), Cuadernos Feijonianos de Historia Moderna IV, Santiago de Compostela, Tórculo Editores, pp. 221-250.

SaAvedra VÁzquez, M. ${ }^{\mathrm{a}}$ del Carmen (1996), Galicia en el Camino de Flandes, A Coruña-Sada, Edicións do Castro.

SAavedra VÁzquez, M. a del Carmen (2004a), «La financiación de la actividad militar en Galicia y sus repercusiones fiscales durante la primera mitad del siglo XVII», en Aranda Pérez, Francisco José (coord.), La declinación de la Monarquía Hispánica en el siglo XVII, Cuenca, Ediciones de la Universidad de Castilla-La Mancha, pp. 433-450.

SAAVedra VÁzquez, M. a del Carmen (2004b), «El coste de la guerra: características $\mathrm{y}$ articulación de las finanzas militares gallegas en la primera mitad del siglo XVII», Revista de Historia Moderna. Anales de la Universidad de Alicante, 22, pp. 343-368. <https://doi.org/10.14198/RHM2004.22.12>.

SaAvedra VÁzquez, M. a del Carmen (2011), «La decadencia del imperio español de los Austrias: algunas consideraciones a partir del caso gallego», Sémata. Ciencias Sociais e Humanidades, 23, pp. 229-251.

SAavedra VÁzquez, M. a del Carmen (2017), «El papel de las elites locales en la organización militar: Galicia, 1668-1715», en García Hernán, Enrique y Maffi, Davide (coords.), Estudios sobre Guerra y sociedad en la Monarquía Hispánica, Valencia, Ediorial Albatros, pp. 519-538.

Salvado Borges, Emilia (2015), A guerra da Restauração no Baixo Alentejo (16401668), Lisboa, Editorial Colibri.

Sanz Camañes, Porfirio (1997), Política, hacienda y milicia en el Aragón de los últimos Austrias entre 1640 y 1680, Zaragoza, Institución Fernando el Católico.

Solano Camón, Enrique (1987), Poder monárquico y estado pactista (1626-1652). Los aragoneses ante la Unión de Armas, Zaragoza, Institución Fernando el Católico.

STOORs, Christopher (2013), La resistencia de la Monarquía Hispánica (1665-1700), Madrid, Actas. 
Thompson, Irving A. A. (1987), «Aspectos de la organización naval y militar durante el Ministerio de Olivares», en García Sanz, Ángel y Elliott, John H. (coords.), La España del Conde Duque de Olivares, Valladolid, Universidad, pp. 251-274.

Truchuelo García, Susana (2004), Gipuzkoa y el poder real en la Alta Edad Moder$n a$, Donostia, Diputación Foral de Gipuzkoa.

Tuero Bertrand, Francisco (1978), La Junta General del Principado de Asturias, Oviedo, Ayalga Ediciones.

Valladares Ramírez, Rafael (1998), La rebelión de Portugal. Guerra, conflicto y poderes en la Monarquía Hispánica (1640-1680), Valladolid, Junta de Castilla y León.

White, Lorraine (1987), «Actitudes civiles hacia la guerra en Extremadura (16401668)», Revista de estudios extremeños, 43 (2), pp. 487-502. 